\title{
Is postoperative radioactive iodine associated with a survival advantage among...
}

\author{
Rasha Hamdy Hamed* \\ Clinical Oncology and Nuclear Medicine, Faculty of Medicine, \\ Mansoura University, MANSOURA, EGYPT
}

Received 11 April 2017; Accepted 24 August 2017

\begin{abstract}
Aim: this trial aimed to determine wether postoperative radioactive iodine(RAl) associated with a survival benefit among intermediate-risk Papillary Thyroid Cancer patients or not.

Methods: this study is a retrospective study of intermediate-risk papillary thyroid cancer patients that were treated with or without post operative RAI from 1st January 2002 till 1stJanuary 2012. Overall survival (OS) and multivariate regression analyses were measured for all patients.

Results: 100 patients were included in this trial : 70 patients received postoperative RAI and 30 patients did not. The mean follow-up time was 7.1 (4.8 -15.1 years), and a median survival time could not be estimated. Overall survival at 10 years was $96 \%$ in the RAI vs $93 \%$ in the group without RAI $(P<.001)$. RAI reduced risk of death by a $27 \%$ [hazard risk (HR) 0.73 , confidence interval (Cl) 0.64 $0.84, \mathrm{P}<.001]$. Older patient age , male gende, larger tumor size, multifocal tumors, lymph node metastases, aggressive histology, vascular invasion, positive surgical margin , minimal extrathyroidal extension and absence of postoperative RAI were accompanied by compromised OS (all $\mathrm{P} \leq .001$ ).

Conclusion: This representative study addresses the survival advantage of RAl for with intermediate risk PTC patients but conducting of large prospective randomized controlled trial is still warranted.
\end{abstract}

Keywords: Postoperative radioactive iodine • intermediate-risk Papillary Thyroid Cancer

(C) De Gruyter Open

\section{Introduction}

Papillary thyroid cancer (PTC) is the most common histology of thyroid cancer. ${ }^{[1,2]}$ Nowadays, PTC represents about $70-85 \%$ of thyroid carcinomas. ${ }^{[3]}$ Patients with PTC have an excellent prognosis with appropriate surgical resection, with or without postoperative radioactive iodine therapy (RAI). ${ }^{[4]}$

In the past, almost every patient with a diagnosis of PTC has received postoperative RAI. Currently, the selection of patient for postoperative RAI depends on the risk-group. The risk indicators depend on some indicators obtained at surgery, postoperative neck ultrasonography and postoperative Tg measurements. ${ }^{[3,5]}$ The American Thyroid Association (ATA) has classified PTC according to recurrence, mortality risks, and the postoperative RAI advantage into three groups: low, intermediate, and high risk. ${ }^{[3]}$

Patients with intermediate-risk may have: microscopic tumour invasion into the perithyroidal soft tissues; vascular invasion; clinical N1 or > 5 pathologic N1 (lymph nodes < $3 \mathrm{~cm}$ in largest dimension); multifocal microcarcinoma; aggressive histology (e.g., tall cell, hobnail variant, columnar cell carcinoma; BRAFV600E mutation; and RAl-avid metastatic foci in the neck on the first post-treatment WBS. ${ }^{[3]}$

Postoperative RAl may act as adjuvant therapy by eradicating cancer microscopic foci, as PTC is frequently multifocal, and by eradicating microscopic lymph node metastases. In addition, aend tail whole body scan ( WBS) can be done after postoperative RAI; the results of this scan may identify previously undiagnosed disease, and may change the initial staging and facilitate early recurrence detection that is based on serum thyroglobulin (Tg) measurement and/or WBS. ${ }^{[6,7]}$

Although $\mathrm{I}-131$ is widely used, RAI therapy is not without adverse consequences. RAI can impact quality of life due to side effects such as acute or chronic xerostomia, acute or chronic sialoadentitis, and dental caries. ${ }^{\left[{ }^{8,9]}\right.}$ Reports of a slightly increased risk of developing secondary primary malignancies after RAI therapy have called for a more selective use of RAI. ${ }^{[10,11]}$ 
The ATA currently recommends adjuvant RAI therapy for high-risk patients and select intermediate-risk cases but not for low-risk patients. ${ }^{[3]}$ Adjuvant RAI therapy has been debated for intermediate-risk patients because of the long-term prognosis of patients in this risk group. In this study, we examined whether postoperative RAl was associated with a survival advantage among patients with intermediate-risk PTC

\section{Materials and Methods}

This study is a retrospective study of patients with papillary thyroid cancer that was treated at the Clinical Oncology \& Nuclear Medicine Department, Mansoura University Hospital during the period from $1^{\text {st }}$ January

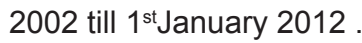

\section{Inclusion and Exclusion criteria}

Patients aged 18 years or older, who had undergone total, near-total, or subtotal thyroidectomy were included. The intermediate risk group was selected for inclusion in our analyses which was defined according to the ATA risk criteria and American Joint Commission on Cancer (AJCC) staging. Patients have: tumour with microscopic tumour invasion into the perithyroidal soft tissues; vascular invasion; clinical N1 or $>5$ pathologic $\mathrm{N} 1$ (lymph nodes $<3 \mathrm{~cm}$ in largest dimension); multifocal microcarcinoma; and aggressive histology (e.g., tall cell, hobnail variant, columnar cell carcinoma were selected for inclusion in our analyses. They were divided into two groups: those who received postoperative RAI therapy and those who did not.

Follicular, Hürthle cell medullary and anaplastic thyroid cancers were excluded. Additional cases were excluded due to missing data for some variables. Patients with more than one primary cancer were also excluded.

\section{Study Variables}

The demographic variables included for the patients were age and gender. Pathological and clinical characteristics included in our analyses were tumour size, lymph node status, margin status, minimal extrathyroidal extension (yes/no), multifocality (yes/no), aggressive variants of PTC, such as poorly differentiated, tall cell, columnar and sclerosing insular variants (yes/no), vascular invasion (yes/no) and RAI administration (yes/no).

\section{Statistical Analysis}

Patient characteristics were reported as frequencies and proportions for categorical variables and SD for continuous variables. Differences between patients who underwent
RAl and those who did not were examined using $x^{2}$ tests and Student's $t$-tests for categorical and continuous variables, respectively. Overall survival (OS) was defined as the time from diagnosis to death or last follow-up, whichever came first. Kaplan-Meier curves were used to visualize OS for those who received RAI versus those who did not, and the log-rank test was used to examine the differences in survival. A multivariate Cox proportional hazards model was used to examine OS after adjustment for clinical and demographic factors. Significance was prespecified at $P=.05$ for all statistical tests.

\section{Results}

A total of $100(43.1 \%)$ of the PTC patients $(n=232)$ met the definition of intermediate risk. Of those, $70(70 \%)$ received RAI and 30 (30\%) did not. Patients who received RAl versus those who did not had a higher proportion of tumour, $2 \mathrm{~cm}$ or more ( $85.8 \%$ vs. $40 \%$, respectively), lymph node involvement ( $85.8 \%$ vs. $26.7 \%)$, multifocal tumours $(49.9 \%$ vs. $33.3 \%)$, aggressive histology ( $28.7 \%$ vs. $13.3 \%)$, vascular invasion $(21.4 \%$ vs. $13.3 \%)$, positive surgical margin status $(21.4 \%$ vs. $16.7 \%)$ and minimal extrathyroidal extension $(21.4 \% \%$ vs. $13.3 \%)$, (all $\mathrm{P}<.001$ ) (Table 1).

The mean follow-up time was 7.1 years (4.8 -15.1 years), and a median survival time could not be estimated. There were 4 deaths $(5.7 \%)$ in the RAI group vs. $3(10 \%)$ in the no RAI group $(P<.001)$. Most patients were alive as of 2012 , and a median survival time could not be estimated. Overall survival at 10 years was $96 \%$ in the RAI group vs. 93\% in the no RAI group ( $P<.001)$. RAI administration was associated with improved OS in all patients as demonstrated by Kaplan-Meier survival curves (log-rank P < .001) (Figure 1).

After multivariate adjustment for patient demographic and clinical factors, RAl was associated with a $27 \%$ reduced risk of death [hazard risk (HR) 0.73 \{confidence interval (CI) 0.64-0.84\}, P < .001]. Patient factors associated with compromised OS included: 'older patient age and male gender'. The pathological and clinical factors associated with compromised OS included; 'larger tumour size, presence of lymph node metastases, multifocal tumours, aggressive histology, vascular invasion, positive surgical margin, minimal extrathyroidal extension and lack of RAI therapy' (all $\mathrm{P} \leq$.001) (Table 2).

\section{Discussion}

Due to the indolent nature of differentiated thyroid cancer and long-term survival, there is a lack of 


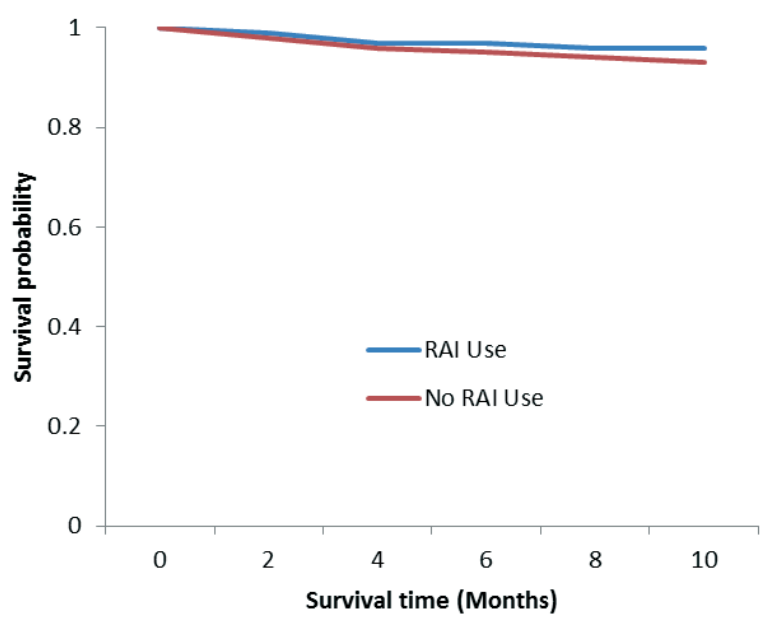

Figure 1. Kaplan-Meier estimates of overall survival in both treatment groups.

Table 1. Characteristics of Patients and Tumors.

\begin{tabular}{|c|c|c|c|c|c|}
\hline \multirow[t]{2}{*}{ Characteristics } & \multicolumn{2}{|c|}{ No RAI } & \multicolumn{2}{|c|}{ RAI } & \multirow{2}{*}{$\begin{array}{l}\mathbf{P} \\
\text { Value }\end{array}$} \\
\hline & & $\mathbf{n}$ & $\%$ & $\mathbf{n}$ & \\
\hline $\begin{array}{l}\text { Age } \\
<45 \\
\geq 45\end{array}$ & $\begin{array}{l}17 \\
13\end{array}$ & $\begin{array}{l}56.7 \\
43.3\end{array}$ & $\begin{array}{l}40 \\
30\end{array}$ & $\begin{array}{l}57.1 \% \\
42.9 \%\end{array}$ & $<0.001$ \\
\hline $\begin{array}{l}\text { Gender } \\
\text { Female } \\
\text { Male }\end{array}$ & $\begin{array}{c}21 \\
9\end{array}$ & $\begin{array}{l}70 \\
30\end{array}$ & $\begin{array}{l}50 \\
20\end{array}$ & $\begin{array}{l}71.4 \% \\
28.6 \%\end{array}$ & $<0.001$ \\
\hline $\begin{array}{l}\text { Tumor size } \\
\text { T1 } \\
\text { T2 } \\
\text { T3 }\end{array}$ & $\begin{array}{l}18 \\
6 \\
6\end{array}$ & $\begin{array}{l}60 \\
20 \\
20\end{array}$ & $\begin{array}{l}10 \\
20 \\
40\end{array}$ & $\begin{array}{l}14.2 \% \\
28.7 \% \\
57.1 \%\end{array}$ & $<0.001$ \\
\hline $\begin{array}{l}\text { lymph nodes } \\
\text { NO } \\
\text { N1<1cm } \\
1:<2 \mathrm{~cm} \\
2:<3\end{array}$ & $\begin{array}{l}22 \\
8 \\
0 \\
0 \\
\end{array}$ & $\begin{array}{l}73.3 \\
26.7 \\
0 \\
0\end{array}$ & $\begin{array}{l}10 \\
10 \\
20 \\
30\end{array}$ & $\begin{array}{c}14.2 \% \\
14.2 \% \\
28.7 \% \\
42.9 \% \\
\end{array}$ & $<0.001$ \\
\hline $\begin{array}{l}\text { Multifocality } \\
\text { Yes } \\
\text { No }\end{array}$ & $\begin{array}{l}10 \\
20\end{array}$ & $\begin{array}{l}33.3 \\
66.6\end{array}$ & $\begin{array}{l}36 \\
34\end{array}$ & $\begin{array}{l}49.1 \% \\
51.9 \%\end{array}$ & $<0.001$ \\
\hline $\begin{array}{l}\text { Aggressive } \\
\text { histology } \\
\text { Yes } \\
\text { No }\end{array}$ & $\begin{array}{l}4 \\
26\end{array}$ & $\begin{array}{l}13.3 \\
86.7\end{array}$ & $\begin{array}{l}20 \\
50\end{array}$ & $\begin{array}{l}28.7 \% \\
71.3 \%\end{array}$ & $<0.001$ \\
\hline $\begin{array}{l}\text { vascular } \\
\text { invasion } \\
\text { Yes } \\
\text { No }\end{array}$ & $\begin{array}{l}4 \\
26\end{array}$ & $\begin{array}{l}13.3 \\
86.7\end{array}$ & $\begin{array}{l}15 \\
55\end{array}$ & $\begin{array}{l}21.4 \% \\
78.6 \%\end{array}$ & $<0.001$ \\
\hline $\begin{array}{l}\text { Positive } \\
\text { margins } \\
\text { Yes } \\
\text { No }\end{array}$ & $\begin{array}{l}5 \\
25\end{array}$ & $\begin{array}{l}16.7 \\
83.3\end{array}$ & $\begin{array}{l}15 \\
55\end{array}$ & $\begin{array}{l}21.4 \% \\
78.6 \%\end{array}$ & $<0.001$ \\
\hline $\begin{array}{l}\text { Extrathyroidal } \\
\text { extension } \\
\text { Yes } \\
\text { No }\end{array}$ & $\begin{array}{l}4 \\
26\end{array}$ & $\begin{array}{l}13.3 \\
86,7\end{array}$ & $\begin{array}{l}15 \\
55\end{array}$ & $\begin{array}{l}21,4 \% \\
78.6 \%\end{array}$ & $<0.001$ \\
\hline
\end{tabular}

randomized clinical trials studying PTC management because a large number of patients would be needed, with extended follow-up and associated high cost. ${ }^{[6]}$ As a result, there is no consensus in the literature regarding the potential benefit of RAI for intermediate-risk patients. As outlined by the ATA, the decision to treat is therefore based on clinical judgment, with particular weight placed on patient's age, histology, tumour size, and lymph node metastases status in combination with other potential risk factors, such as the presence of tumour multifocality and vascular invasion.[3]

Currently, the intermediate-risk group has not been analyzed because other studies used alternate risk and staging definitions instead of the ATA definitions, or studies were designed lacking stratifying patients into an intermediate risk category. ${ }^{[12,13,14]}$

This representative study addresses the association between RAl and the survival for patients with intermediate-risk PTC. Although mortality from PTC is low and the disease is generally associated with an excellent prognosis, we observed a $27 \%$ reduced risk of death [hazard risk (HR) $0.73(\mathrm{Cl} 0.64-0.84), \mathrm{P}<.001]$ in our multivariate analyses when RAI was administered in the postoperative setting. Our results suggest that $\mathrm{RAI}$ is associated with improved OS in intermediaterisk patients with papillary thyroid cancer. Our findings support previous studies suggesting that RAI survival benefit in older patients. ${ }^{[12,13]}$

Our finding of a reduced risk of death associated with RAI administration is in contrast to the results of two other large studies: 'using the Surveillance, Epidemiology, and End Results (SEER) database, and a single-institution study from the Mayo Clinic that provided extended patient follow-up'. ${ }^{112,14]}$ Although neither study examined the intermediate-risk group specifically, both studies failed to show a survival benefit for RAI therapy among the patients, overall. ${ }^{[12,14]}$

Podnos et al. ${ }^{[12]}$ (12) failed to show an overall survival benefit associated with RAI on multivariate analysis (median follow-up of 95 months) among 12661 PTC patients using the SEER database $(P=.9176)$ However, this study identified improved survival with RAl only among patients who had all of the following risks: patient's age older than 45 years, tumour size greater than $2 \mathrm{~cm}$, positive lymph nodes, and distant metastases.

In a large, single-institution, a retrospective study conducted at the Mayo Clinic, Hay et al. ${ }^{[14]}$ found no disease specific survival or recurrence benefit when RAI therapy was used among patients with papillary thyroid cancers, deemed to be low risk or high risk. In this study, a MACIS prognostic score: 'distant metastasis, patient's age, completeness of resection, local invasion, and 
Table 2. Multivariate analysis of 100 patients with intermediate-risk papillary thyroid carcinoma.

\begin{tabular}{l|ll}
\hline & HR (95\% CI) & P Value \\
\hline \hline Age & & \\
$<45$ & 1.00 & $<0.001$ \\
$\geq 45$ & $1.36(0.94-1.92)$ & \\
\hline Gender & & $<0.001$ \\
Male & $0.73(0.65-0.82)$ & \\
Female & 1.00 & \\
\hline Tumor size & & \\
T1 & 1.00 & $<0.001$ \\
T2 & $0.62(0.49-0.78)$ & \\
T3 & $0.74(0.56-0.97)$ & $<0.001$ \\
\hline lymph nodes & & \\
N0 & 1.00 & $<0.001$ \\
N1 & $1.45(1.05-2.12)$ & \\
\hline Multifocality & & $<0.001$ \\
Yes & $0.83(0.75-0.92)$ & \\
No & 1.00 & $<0.001$ \\
\hline Aggressive histology & & \\
Yes & $0.94(0.58-1.66)$ & \\
No & 1.00 & \\
\hline vascular invasion & & \\
Yes & $0.98(0.68-1.56)$ & \\
No & 1.00 & \\
\hline Positive margins & $1.55(1.15-2.22)$ & \\
Yes & 1.00 & \\
No & & \\
\hline Extrathyroidal extension & $0.62(0.49-0.78)$ & \\
Yes & 1.00 & \\
No & 1.00 & \\
\hline RAl use & $0.72(0.59-0.88)$ & \\
No & & \\
Yes & & \\
\hline & & \\
\hline
\end{tabular}

tumour size' with a score of less than 6 was deemed to be low risk, and a score of 6 or greater was assessed as high risk. ${ }^{[14]}$ Due to a difference in risk definitions, the Mayo Clinic study examined low and high risks and did not directly evaluate patients at intermediate risk.

As part of the National Thyroid Cancer Treatment Cooperative Study Group (NTCTCSG), a prospective multi-institution registry of 11 North American institutions, Jonklaas et al. ${ }^{[13]}$ found a survival benefit for adjuvant RAl used in a subset of intermediate-risk patients. Using multivariate regression and propensity score analyses, they found that RAI administration was associated with improved overall survival in NTCTSG stages II, III, and IV papillary thyroid cancers. They also found improved disease-specific survival and reduced recurrence rates with RAI use among patients with NTCTSG stages III and IV, but not stage II, disease. In contrast to our study, Jonklaas et al. used an alternative NTCTCSG staging system and did not specifically analyze the ATA intermediate-risk patients. Depending on the patient's age, intermediate-risk patients can fall into NTCTSG stages I-III. Although Jonklaas et al. found benefit with RAl among a subset of intermediate-risk patients, no benefit was seen in NTCTCSG stage I patients, which includes some intermediate-risk patients younger than 45 years. In contrast, our study found RAI administration was associated with OS benefit in all intermediaterisk patients, as defined by ATA criteria, regardless of patient's age..

Our finding of a reduced risk of death associated with RAl administration is in agreement to results of one large study ${ }^{[15]}$ in which, Ewa Ruel et al. observed a $29 \%$ reduced risk of death hazard ratio of 0.71 in intermediate-risk PTC patients. Overall survival in patients younger than 45 years ' $36 \%$ reduction in risk of death with a hazard ratio of 0.64 ' was improved by using RAI. ${ }^{[15]}$ However, the unavailability of the number and dimension of lymph node metastases were an important limitation of this study. ${ }^{[16]}$

Recent studies reported that increasing number of lymph node metastases and macroscopic lymph node metastases were associated with decreasing overall survival, ${ }^{[17,18]}$ these finding are in agreement with our results.

The limitations of this study include: small number, retrospective, and single institution. Additionally, some variables of interest were incomplete, for example, patient preference, patient comorbidities, information on post-RAl therapy whole-body scans and disease recurrence. An important limitation of our study is that it does not provide disease specific survival information; therefore, we could analyze only overall survival.

A large prospective randomized controlled trial is warranted; however, the indolent nature of thyroid cancer and the high costs of conducting such study have made this difficult in the past.

\section{Conclusion}

This representative study addresses the survival benefit of RAI for patients with intermediate-risk PTC, but conducting of large prospective randomized controlled trial is still warranted. 


\section{References}

[1] American Cancer Society. 'Cancer facts, figures2013.http://www.cancer.org/acs/groups/ content/@epidemiologysurveilance/documents/ document/acspc-036845.pdfAccessed' November 30, 2014.

[2] DeSantis CE, Lin CC, Mariotto AB, et al. 'Cancer treatment and survivorship statistics', 2014. CA Cancer J Clin. 2014;64:252-271.

[3] Haugen BR, Alexander EK, Bible KC et al. 'American thyroid association management guidelines for adult patients with thyroid nodules and differentiated thyroid cancer: The American Thyroid Association Guidelines Task Force on Thyroid Nodules and Differentiated Thyroid Cancer.' Thyroid. 2016; 26(1):1-133.

[4] Davies L, Welch HG. 'Thyroid cancer survival in the United States: observational data from 1973 to 2005'. Arch Otolaryngology Head Neck Surg. 2010;136:440-444.

[5] Jonklaas J, Sarlis NJ, Litofsky D, et al. 'Outcomes of patients with differentiated thyroid carcinoma following initial therapy'. Thyroid. 2006;16:12291242.

[6] Morris LF, Romero Arenas MA, et al. 'Streamlining variability in hospital charges for standard thyroidectomy: developing a strategy to decrease waste.' Surgery. 2014;156:1441-1449.

[7] Castagna, M. G., S. Cantara, and F. Pacini. 'Reappraisal of the indication for radioiodine thyroid ablation in differentiated thyroid cancer patients: Journal of Endocrinological Investigation.' 2016; 39:1087-1094.

[8] Mendoza A, Shaffer B, Karakla D, et al. 'Quality of life with well-differentiated thyroid cancer: treatment toxicities and their reduction.' Thyroid. 2004;14:133140.[PubMed]

[9] Almeida JP, Sanabria AE, Lima EN, et al.. 'Late side effects of radioactive iodine on salivary gland function in patients with thyroid cancer.' Head Neck. 2011;33:686-690.[PubMed]

[10] Sawka AM, Thabane L, Parlea L, et al. 'Second primary malignancy risk after radioactive iodine treatment for thyroid cancer: a systematic review and meta-analysis.' Thyroid. 2009;19:451-457. [PubMed]
[11] lyer NG, Morris LG, Tuttle RM, et al. 'Rising incidence of second cancers in patients with lowrisk (T1N0) thyroid cancer who receive radioactive iodine therapy.' Cancer. 2011;117:4439-4446.[PMC free article][PubMed]

[12] Podnos YD, Smith DD, Wagman LD, et al. 'Survival in patients with papillary thyroid cancer is not affected by the use of radioactive isotope'. .J Surg Oncol. 2007;96:3-7.[PubMed]

[13] Jonklaas J, Sarlis NJ, Litofsky D, et al. 'Outcomes of patients with differentiated thyroid carcinoma following initial therapy.' Thyroid. 2006;16:12291242.[PubMed]

[14] Hay ID, Thompson GB, Grant CS, et al. 'Papillary thyroid carcinoma managed at the Mayo Clinic during six decades (1940-1999): temporal trends in initial therapy and long-term outcome in 2444 consecutively treated patients.' .World J Surg. 2002;26:879-885.[PubMed]

[15] Ewa Ruel, Samantha Thomas, Michaela Dinan, et al. 'Adjuvant Radioactive lodine Therapy Is Associated With Improved Survival for Patients With Intermediate-Risk Papillary Thyroid Cancer.' J ClinEndocrinolMetab. 2015 Apr; 100(4): 15291536.

[16] M. G. Castagna1, S. Cantara, F. Pacini. 'Reappraisal of the indication for radioiodine thyroid ablation in differentiated thyroid cancer patients.' J Endocrinol Invest (2016) 39:1087-1094

[17] Adam MA, Pura J, Goffredo P et al . 'Presence and number of lymph node metastases are associated with compromised survival for patients younger than age 45 years with papillary thyroid cancer.' J ClinOncol. 2015;33:2370-2375

[18] Randolph GW, Duh QY, Heller KS et al. 'The prognostic significance of nodal metastases from papillary thyroid carcinoma can be stratified based on the size and number of metastatic lymph nodes, as well as the presence of extranodal extension.' Thyroid.2012 22:1144-1152 